\title{
Uncompleted Fullerenelike Structures: Synthesis and Chracteristics
}

\author{
Kasumov Mais \\ E-mail: kasumova@meta.ua, Kyiv, Ukraine \\ Received: August 5, 2021 Revised: September 15, 2021. Accepted: September 17, 2021. \\ Published: September 21, 2021.
}

\begin{abstract}
The literature is considering completely formed fullerenes as usually. Without attentions have been left uncompleted ones, and their properties are practically unknown. Such structures may be received at arc discharge synthesis in the limited space with short time of synthesis. Here synthesis was made at arc discharge chamber with little radius and less gas flow. The time-of-flight mass spectrum synthesized product on $\mathrm{m} / \mathrm{z}$ size showed containing of hydrated uncompleted-composite fullerene. They were like with structures: $\mathrm{C}_{54} \mathrm{H}_{4}, \mathrm{C}_{56} \mathrm{H}_{4}$, $\mathrm{C}_{56} \mathrm{H}_{8}, \mathrm{C}_{68} \mathrm{H}_{4}$ and other. A presence at mass spectrum of abnormal structures was manifested in form of doublet many-peaks lines. They also confirmed termperatureformating of new bonds with successive griping valence bonds with poliin structures at arc discharge. From mass spectrum, on base of Mendileive's chemical plate was supposed the way forming conjectural structure. The MS-picture was confirmed with estimation for forming many-peaks abnormal poliin like structures.
\end{abstract}

Keywords: carbinofullerene, many-peaks lines, twin one-atom carbin.

\section{INTRODUCTION}

Within past decades after discovery [1-3] of hollow reserved carbon frameworks, which are known as fullerenes now, they turned into perspective materials for decision of problem objects of medicine, biology, science and technology [4-6]. Now to $25 \%$ of newest technologies are founded on using of $\mathrm{C}_{60}, \mathrm{C}_{70}$ [7], and arisen directions of technologies have to be calculated upon using of heavy fullerenes $\mathrm{C}_{76}, \mathrm{C}_{84} \ldots \mathrm{C}_{90}$, which have more cross section and energy of the adiabatic electron affinity. These are completed fullerenes, those carbon frameworks have high symmetry and they are formed with pentagons, hexagons only and it's the direction for search of a new carbon allotrope's forms. Without attention of a wide investigators' circle of nature real object remains "uncompleted fullerene like structures", or "predecessors" of fullerene $\mathrm{C}_{60}$. These structures $\mathrm{C}_{50}, \mathrm{C}_{52}, \mathrm{C}_{54}, \mathrm{C}_{56}, \mathrm{C}_{58}$ were marked in mass spectrum (MS) of arc discharge product, which was received with a little interelectrod space $(\mathrm{d}<2 \mathrm{~mm})$ [8]. The main result is that MS was got under the electron bunch with energy of $7 \leq \mathrm{E} \leq 100 \mathrm{eV}$. Authors of this article called the form of arc discharge for "predecessors" as "contact graphite discharge" (CGD). There are the like structures for fullerenes $\mathrm{C}_{70}, \mathrm{C}_{84}$ and others also. The CGD's structures have frameworks with any departure from the norm symmetry. These structures are formed with carbon pentagons, hexagons and others many-corners structures.

At given work a product of arc discharge, which was got at limited space in work discharge pressure slightly more than an 
atmosphere. The product was researched on the up-to-date mass spectrometer.

The aim of the work was a research of condition for formation uncompleted, fullerenelike structure and to find mechanism of forming arc discharge fullerene's variety, which has a little presentation in the literature. These were uncompleted fullerene, and they were nearly $\mathrm{C}_{60}$ and $\mathrm{C}_{70}$. In the literature for this fullerene like structures we have used term which was occurred from carbine like components [9].

\section{EXPERIMENTAL PART AND METHODS}

A stock-produced TDM-317 as welding power source with dropping current-voltage characteristic and a pulsed arcing stabilizer were used jointly [10].

The synthesis was carried out in a discharge chamber of $37 \mathrm{~mm}$ diameter, $\mathrm{h}_{1}=100 \mathrm{~mm}$. On Fig. 1 shown a semi-scheme of interelectrode work space, where graphite electrodes for emission spectrum analysis is a rod diameter $\varnothing$ $=2 \mathrm{R}=6 \mathrm{~mm}$ and semi-disk $20 \mathrm{~mm}$ diameter, $\mathrm{h}_{2}=10 \mathrm{~mm}$, and an interelectrode work space is $\mathrm{H}$. The electrode holders and chamber walls are water-cooled.

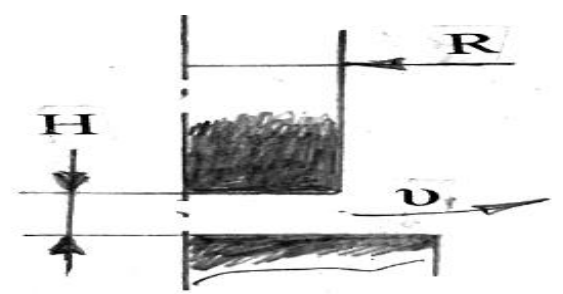

Fig.1. A semi-scheme of interelectrode work space with marked in the text components: $\mathrm{R}, \mathrm{H}$ and a gas-plasma flow's $v$ velosity.

The estimated size $\mathrm{H}$ for synthesis of uncompleted fullerenes, as in CGD, was received from the next physical sense. It was deduced a formula from the preservation of matter low: let's we have any $\mathrm{F}^{+}>\mathrm{F}^{-}$, where $\mathrm{F}^{+}$ $=\pi \mathrm{R}^{2}$ is a surface of electrode evaporation, $\mathrm{F}^{-}=$ $2 \pi \mathrm{RH}$ is a conditional surface for going out of evaporation stream. After simplification and substitution of experimental sizes we have the estimated size of an interelectrode space $\mathrm{H} \leq$ $1.5 \mathrm{~mm}$. So the estimated length of trajectory fullerenelike forming is $\mathrm{L}^{*} \approx 2 \mathrm{H} \approx 3 \mathrm{~mm}$.
It was being studied the MS of a fullerene sample, which was synthesized at arc current of $100 \mathrm{~A}$, with a flow helium rate $\mathrm{q}=2 \mathrm{~cm}^{3} / \mathrm{s}$, and in discharge chamber pressure $\mathrm{p} \approx 0,11 \mathrm{MPa}$. After ignition of arc discharge between graphite electrodes is generated a gas-plasma stream, going out with $v$ velocety from the discharge space. It owing to carbon evaporation of little electrode, working gas flow and energy of discharge, putten up between electrodes. The velocity of stream was defined by the size of arc current, the radius of electrode, the pressure and temperature $(\mathrm{T}>1500 \mathrm{~K})$ of work gas. The estimation of stream speed with help of equation from [11] has given $v \approx 100 \mathrm{~m} / \mathrm{s}$. Now the estimated duration of fullerene formation time had to be received from known experimental parameters of unit and the simple ratio $\tau^{*}=\mathrm{L}^{*} / v \approx 3 \cdot 10^{-5} \mathrm{~s}$.

The composition of the arc synthesis product was determined on AUTOFLEX ${ }^{R}$ IILRF 20 apparatus with $\mathrm{N}_{2}$ laser from a timeof-flight mass spectrum [12]. The fullerenes were extracted from soot in benzene. It was not preliminary cleaned, and fullerene sample for MS was prepared at a free atmosphere on $\mathrm{Al}$ $\left(\mathrm{Al}_{2} \mathrm{O}_{3}\right)$ or swtainless steel substratum.

\section{RESULTS AND DISCUSSION.}

\section{A. Scheme fullerene forming.}

The MS of product [13] with positive charge on Fig.2a and with negative charge on Fig.2b there were in range of $200<\mathrm{m} / \mathrm{z}<1400 \mathrm{u}$. The greatest peak divides MS on two parts. In the left part of spectra there are a few little peaks of intermediate particles and there is beginning goal's product. The spectra showed about on absence of fullerene fragment's peaks, and it was nearly constant background at $\mathrm{m} / \mathrm{z}<720 \mathrm{u}$.

On Fig.2a at $(\mathrm{m} / \mathrm{z})>1200 \mathrm{u}$ there was no fullerene's peaks practically, but on Fig.2b there were recorded particles about of all range. These spectra properties were explained with increasing of the size adiabatic electron affinity and cross-section with gaining of number carbon atoms. The scheme of process forming product in Fig.2a is the next. After capture of discharge electron, that is: $\mathrm{C}_{\mathrm{n}}{ }^{+}+\mathrm{e} \rightarrow \mathrm{C}_{\mathrm{n}}{ }^{0}$, where $n \geq 100$ is neutralized and therefore it didn't registered particles in MS [14]. And 
the synthesized product in the processing was modified. The process went up in during extraction from soot in benzene $\left(\mathrm{C}_{6} \mathrm{H}_{6}\right)$, in free atmosphere and on the surface of substratum at presence any track of water.

The synthesized material is able to contain clusters, consisted of components: H, C, O. For confronting of the $\mathrm{m} / \mathrm{z}$ peaks of MS from Fig.2a and Fig.2b. And to definite clusters with a marked before atoms, was used the analitical ratio including these components [13]:

$$
\begin{gathered}
\mathrm{M} / \mathrm{Z}\left(\mathrm{C}_{\mathrm{n}} \mathrm{O}_{\mathrm{y}} \mathrm{H}_{\mathrm{x}}\right)=12 \cdot \mathrm{n}+16 \cdot \mathrm{y}+\mathrm{x} \\
\text { here } \mathrm{n}, \mathrm{y}, \mathrm{x}-\text { integers, } \\
\text { and } \mathrm{n} \geq 1, \mathrm{y} \geq 0 \text { and } 0 \leq \mathrm{x}<16
\end{gathered}
$$

On Fig.2a and Fig. $2 b$ there are three the biggest peaks. For them the equality (1), (2) and (3) with $y=x=0$ correspond to fullerenes $\mathrm{C}_{60}$, $\mathrm{C}_{70}$ and $\mathrm{C}_{84}$. They have corresponding $(\mathrm{m} / \mathrm{z})^{+}$ lines: 719,672, 839,608, 1007,579 and with size $(\mathrm{m} / \mathrm{z})^{-}$lines: 719,381, 839,375, 1007,418, which after round off to integers, had $\mathrm{m} / \mathrm{z}$ values: 720,840 and 1008 .

Fig. 2.

Using relationships (1) - (3) and abovementioned remarks it was built Table 1 for 10 lines from MS in Fig.2a and Fig.2b. The data of Table 1 will be analysed further.

\section{Table 1.}

The estimate of the product peak size from Fig.2a and Fig.2b with number of carbon atoms for $\mathrm{C}_{60}, \mathrm{C}_{70}$ and $\mathrm{C}_{84}$ (in relative units) given: $1.00,0.92$ and 0.31 . The result may be taken for model of successive fullerene forming.

The fullerene forming is going at arc discharge with temperature $\mathrm{T}>1000 \mathrm{~K}$ as a result of collisions at the diffusion motion in gas-plasma conducting medium, as sequence of connect acts clusters $C_{k}, n_{i} C_{i}$ and reverse acts annealing clusters $n_{f} C_{f}$. So the general scheme :

$$
\mathrm{C}_{\mathrm{j}}=\mathrm{C}_{\mathrm{k}}+\left.\sum\right|_{\mathrm{i}} \mathrm{n}_{\mathrm{i}} \mathrm{C}_{\mathrm{i}}-\left.\sum\right|_{\mathrm{f}} \mathrm{n}_{\mathrm{f}} \mathrm{C}_{\mathrm{f}}
$$

Here $\mathrm{C}_{\mathrm{k}}$ - is any inition cluster-foetus, made in interelectrode space; $n_{i}$ and $n_{f}$ are integers. Clusters summerize in (4) going on $i, f$ indexes.

\section{B. Fullerene peaks and Bernoulli's Formula}

The diffusion character of movement forming particles at arc discharge gave to clusters spreading in parameters trajectory, mass and on quality. At that there were normal many-peaks and there were abnormal double many-peaks. Accordingly there were two causes for them. The first cause there are always and they are well-known for the isotopic nature earth's graphite in Fig.2b. The other cause there is in Fig.2a. They are owing to synthesis' conditions.

The first cause is involved with isotopic composition of natural material. There are three natural carbon isotopes: ${ }^{12} \mathrm{C},{ }^{13} \mathrm{C}$ and ${ }^{14} \mathrm{C}$. The last carbon isotop contained in nature with to $0.001 \%$ only. So further in calculation was relyed on two main (p, q) carbon componentes only. For the reliable existence of components $p$ and $\mathrm{q}$ is defined with an equality $\mathrm{p}+\mathrm{q}=1$. Now it is supposed if the packet contains $n$ of all particles units and contains $m$ units of them are admixture for convenience. Then a probability selection of $P_{n}(m)$ from that packet is defined on binomial Bernoulli's formula [15]:

$$
P_{n}(m)=C^{m}{ }_{n} \times p^{n-m} \times q^{m} .
$$

On base of the Eq. (5) was taken calculation of isotopic composition of $\mathrm{C}_{60}, \mathrm{C}_{70}$, and $\mathrm{C}_{84}$ with supposing that the main component of natural graphite is an isotop ${ }^{12} \mathrm{C}$, which part is $98.9 \%$. The calculation was done for completed fullerenes, as they have known structures, which is done with hexagons and pentagons [6]. Results of calculation of the probability to select clusters are in Table 2.

\section{Table 2.}

At the upper line of Table 2 is an absolute probability of selection clusters with $m$ number admixture from general $n$ carbon atoms. In the second line is a probability of selection clusters relative to unadmixture component, which is the first line in every packet. In Table 2 there is, a less structure has a narrower mass spectrum. These structures are just for the second packet (Fig.3, Fig.4) and even for the third packet (Fig.3) in every doubled many-peak. The general number of these anomalous structures in Fig. 2a and Fig. 2b are more then 10. 
It's supposed the calculated results (5) can be used for uncompleted fullerenes also. Calculation for the results with taken hydrogen atoms are shown in Fig.3 and Fig.4, and they in close accordance to data of Table 2. The relative sizes of the main and the next packets are depending on number of carbon atoms. It should be noted that even an appearance of the second structures (doubled or triplex manypeaks) is the proof of presence modifications of uncoupled fullerenes.

At our preliminary study MS's of arc discharge in product was marked $\mathrm{C}_{50}$, and the number of second structures packets always not more then three. It's shown on Fig.3. In a different way, if the modification would be absent, the second structures of doubled manypeaks would be absent too.

\section{The detection of modificater ()}

To define the nature of modificater was carried out a calculation of general size (GS) of the selected packets $\Delta(\mathrm{m} / \mathrm{z})$ from MS in Fig. 3 and Fig.4. The calculation GS is possible to do with measuring of distance between the main (the first) packet's peaks or to do this with measuring of distance between minimums of packets. The last observation was marked at the analysis results of Table 2 . The results of GS and 2 GS measuring there were:

$$
\begin{aligned}
(\mathrm{m} / \mathrm{z}) & =4.2 \pm 0.2(\mathrm{u}), \\
2 \Delta(\mathrm{m} / \mathrm{z}) & =8.4 \pm 0.4(\mathrm{u})
\end{aligned}
$$

The quantities from (6) and (7) can be bringing into correlation with modificater's mass of uncompleted fullerenes $\mathrm{C}_{56}, \mathrm{C}_{58}$ and $\mathrm{C}_{68}$. From the periodic Mendeleev's table the sizes GS and 2GS from (6) and (7) are in correspondence to the next modificater's masses only:

$$
\begin{gathered}
\Delta(\mathrm{m} / \mathrm{z})=4.2 \pm 0.2(\mathrm{u}) \approx \\
\approx 4 \cdot 1.008=4.032=4 \mathrm{~m}_{\mathrm{H}}=4 \mathrm{H}, \\
\text { and } 2 \Delta(\mathrm{m} / \mathrm{z})=8.4 \pm 0.4(\mathrm{u}) \approx \\
\approx 8 \cdot 1.008=8.064=8 \mathrm{~m}_{\mathrm{H}}=8 \mathrm{H}
\end{gathered}
$$

The data of (8) and (9) with equalities (1) (3) were used earlier [14], and a part those results are presented in Table 1. So in Fig.3 and Fig. 4 we have two collections of isocarbons, \%: $\mathrm{C}_{56}{ }^{+}$(42), $\mathrm{C}_{56} \mathrm{H}_{4}{ }^{+}$(43) and $\mathrm{C}_{56} \mathrm{H}_{8}{ }^{+}(15) ; \mathrm{C}_{68}{ }^{+}(28)$ and $\mathrm{C}_{68} \mathrm{H}_{4}{ }^{+}(72)$.

The places for fastening of modificater's mass $4 \mathrm{H}$ and $8 \mathrm{H}$ are defects of carbon structures in general. For more accurate definition of the place we used results [6] and [7], where was shown the place of rupturing marked with $\mathrm{B}_{66}$. The symbol $\mathrm{B}_{66}$, as it's usual, designates general bonds for neighbouring carbon hexagons. As for any like example, it was used data of [17] with computer numerical modeling. There was shown also the tempera ture-rupturing of $\mathrm{C}_{46}$ carbon frameworks. In it the processing were successive forming structures of two-, four- and sixth-atoms carbine chains, which have twofold poliin structures. But we had to note, that the numerical modeling was made without calcultion real experemental collisions. But nevertheless, as for as at [18] and in our cases there was the general hexagons' carbon nature [9]. We suppose temperature-rupturing and temperatureformation of new bonds has been going on the same ways with poliin structures.

From analise data on Fig.3, Fig.4 and data of (6) - (9); it was believed that uncompleted fullerenes after process sinthesis at hight temperature were preserved before immersion on bensol. Then, as an example, for our case structures of uncompleted fullerenes were in one-two steps before neighbouring hexagons with strong bonds. The uncompleted fullerenes, as was supposed with marked before data, can include structure shown in Fig.5a, with eight corners and two marked carbon atoms, which were formed with free valent 2 ties for every one. Marked in Fig.5 carbon atoms may be made after blowing up the general tie.

In many-corner Fig.5a there were structural elements of graphene. They are lines with marked points. After arc synthesis in free atmosphere on two free valent-bonds of two marked carbon atoms after chipping off from molecule water are fastened four hydrogen atoms as in Fig.5b. In this way a general scheme for hydro action of cluster $C_{k}(k=8)$ have the form:

$$
C_{k-n}+C_{n} H_{2 n} \rightarrow C_{k} H_{2 n}
$$


In scheme (10) number $n=2$ or 4 was a number of carbon atoms in carbinoid chains.

On Fig.5a and Fig.5b was shown an example of transformations for $n=2$. We suppose the case with $n=4$ have alternatives for bonds in one cluster: 4 or $4=2+2$.

The last option at arc discharge, evidently, has more reality in view of the fact that processes are going by collisions with other clusters, electrons and high temperature at discharge space. The appearance of the second marked uncompleted fullerene structures was the short duration of process forming, and it is, apparently, connected with any part of the space isomering carbon clusters [19] and [20] too.

\section{CONCLUSION}

--- In arc discharge synthesis fullerene similar to CGD's with uncompleted $\mathrm{C}-\mathrm{C}$ bonds are combined structural elements of graphene like and two coupled carbine chains with one atom in every chain, and so these structures has to be named couplecarbin- and couplegraphenefullerene or twincarbin- and twingraphenefullerene.

--- There would be any uncertainty at offered names, because chain with one-atom was not taken to carbine, but here was shown for the simplest bunch of two hexagons that there are twin one-atom carbine chains also.

--- Here was shown that in arc synthesis there was a real opportunity to do a chemical active form of fullerenelike carbon clusters and based on them composites would have more strong structure then with Vander-Vaal's only.

--- The offered method of arc synthesis fullerenelike structures with a less length of trajectory and a less duration formation is other extreme about method of arc discharge in working gas flow (ADHE-WGF) [21], where the new results were reached by increasing a length of trajectory and duration of formation, and not observed any uncompleted fullerenes at all. So here were offered two methods and two devices which have principal distinctions.

\section{REFERENCES}

[1.] D. A. Bochvar, E. G. Galpern. / On hypothetical systems: carbo- dodeca- hedron, sicosahedron and carbo-s-icosahedron. Reports of the USSR Academy of Sciences. -1973. Vol.209.-P.610-612.

[2.] Kroto H. W., Heath I. R. and O'Brien S. C., Curl R. F., Smally R. E. C60: Buckminsterfullerene./Nature.- 1985.- V.318.P.162-163.

[3.] Kratschmer W., Lowell D. Lamb, Fostiropulos K., Donald R. Huffman. Solid C60: A new form of carbon. / Nature.-1990.V.347.-No.6291.- P.354- 358.

[4.] Takada H.,Mimura H., Xiao L., Islam R.M., Matsubayashi K., Ito S., Miwa N. Innovative anti -oxidant: Fullerenes INCI \#:7587) is as "Radical Sponge" on the skin. Its High level of safety, stability and potential as premier antiaging an whitening cosmetic ingredient./Book of Abstracts 7-Th Biennial International Workshop Fullerenes \& Atomic Clusters. St. Peterburg, Russia July 1, 2005.P.59.

[5.] Whitesiders J., EiglerD.,Anders R.et al. Nanotechnology in the Next Decade. Prediction of the Line of Research./ Translated from English.- M.: Mir, 2002.-292 p.

[6.] L. N. Sidorov, M. A.Yurovskaya et al. Fullerenes: Tutorial / M: Publishing house «Ekzamen», 2005.- 688p.

[7.] Grushko Yu. S., V. P. Sedov, Shilin V. A. Technology for production of pure fullerenes C60, C70 and higher fullerenes concentrate. / Journal of Practical Chemistry-2007.ed.3.Vol.80, P.450-457.

[8.] Afanasyev D., Blinov I., BogdanovA., Dyuzhev G., Karataev V., Kruglikov A. Formation of fullerenes in arc. /Technical Physics Journal.1994. - Vol.64.-B.10. P. 76-90. [9.] E. A. Belenkov, I. V. Shahova, Structure of carbinanotubes and carbinofullerenes. /Fizika Tverdogo Tela, 2011,Vol.53, No.11, pp. 2265 2272.

[10.] M.M. Kasumov. On the Limiting Yield of Fullerene Synthesis. /International Journal of Mathematics and Computational Science 
(IJMCS), Vol. 1, Issue 4, 2015, Pages: 166173.

[11.] Ramakrishnan S., Stokes A.D. and Lowke J.J. An approximate model for high - current free -burning arcs./J.Phys.D.: Appl.Phys.1978.V.11,pp 2267-2280

[12.] www.bruker.ru Bruker Daltonics- autoflex II \& autoflex II TOF/TOF.

[13.] M. M. Kasumov, L. V. Osaulenko, V. V. Pokropivnyi, Synthesis and Modification of fullerenes in arc discharge, Ukrainskii Khimicheskii Zhurnal, vol.63,issue 12,pp.77-82 (2007).

[14.] M. M. Kasumov, V.Ya. Chernyak, The arc discharge with a directional gas flow synthesis and properties of fullerenes. The paper has been publicated in International Journal of Engineering and Advanced Technology Studies (IJEATS) vol. 4, iss.1 (March) 2016, pp.11-20. [15.] http:// wikimediafoundation.org

[16.] M.M. Kasumov.Peculiarities of the formation of heavy fullerenes, obtained in arc plasma, and their electronic properties.Manuscript. Dissertation for the degree of candidate of physicomathematical sciences, speciality 01.04.07: solid-state physics. V.I. Vernadskii Institute of General and Inorganic Chemistry of the Ukrainian NAS, Kyiv, 2013. [17.] A.I. Podlivaev, L.A. Openov, Specificity of formation of defects in fullerene C46. /Fizika Tverdogo Tela, 2012, Vol. 54, No. 7, pp. 14171623.

[18.] A.I. Podlivaev, L.A. Openov, Izomers of fullerene C46 with carbin chains./Fizika Tverdogo Tela, 2012, Vol. 54, No. 8, pp. 16141618.

[19.] Thrower, P.A. (1969). "The study of defects in graphite by transmission electron microscopy" Chemistry and Physics of Carbon. 5: 217-320.

[20.] Stone, A. J.; Wales, D. J. (1986). "Theoretical studies of icosahedral C60 and some related structures". Chemical Physics Letters. $128 \quad$ (5-6): 501-503. Bibcode:1986CPL...128..501S.

DOI:10.1016/0009- 2614(86)80661-3.
[21.] M. M. Kasumov, V. V. Pokropivnyi, Zhurnal Tekhnicheskoi Fiziki, 2007, V. 77, issue 7, pp 136-138. Kasumov M. M, Pokropivnyi V. V. Increase in fullerene yield in arc discharge by the action of a gas flow in a hollow electrode, Technical Physics, 2007, Vol. 52, pp. 956-958. DOI: $10.1134 / \mathrm{S}$ 10633784207070237

\section{Creative Commons Attribution License 4.0 (Attribution 4.0 International, CC BY 4.0)}

This article is published under the terms of the Creative Commons Attribution License 4.0

https://creativecommons.org/licenses/by/4.0/deed.en_US 


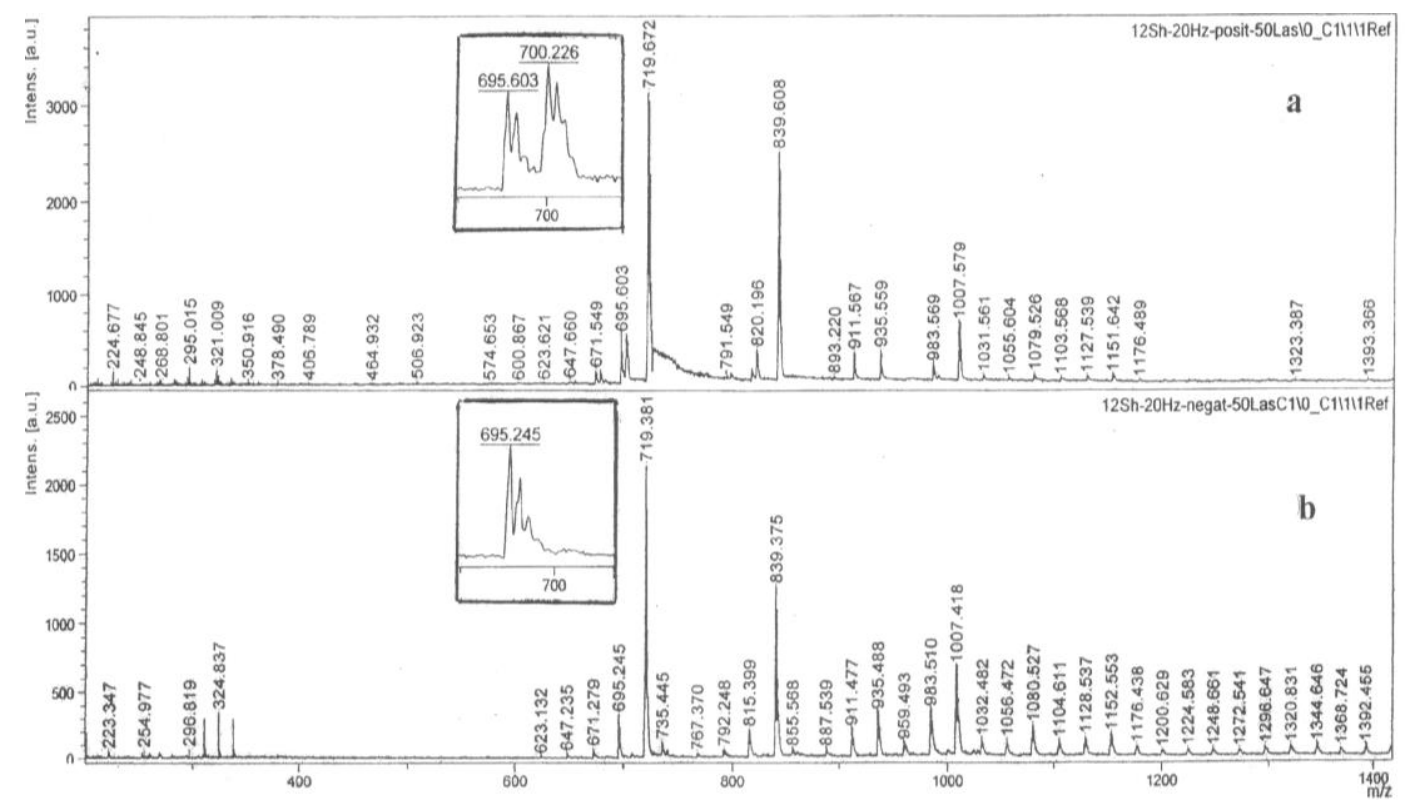

Fig. 2. Mass spectra fullerene's ions received at $J_{\sim}=100 \mathrm{~A}, \mathrm{q}=2 \mathrm{~cm}^{3} / \mathrm{s}$, a - with positive charge, $b$ - with negative charge. On insertions there are peaks at increased look [13].

Table 1. Correspondence of positive $(M / Z)^{+} u$ and negative $(M / Z)^{-} u$ lines $M S^{\prime}$ from Fig.2a and Fig.2b with compositions defined with ratios (1), (2) and (3) [13].

\begin{tabular}{|c|c|c|c|}
\hline$(\mathrm{M} / Z)^{+}, \mathrm{u}$, Fig.2a & Composition & $(\mathrm{M} / Z)^{-}, \mathrm{u}$, Fig.2b & Composition \\
\hline 647.660 & $\mathrm{C}_{54}{ }^{+} ; \mathrm{C}_{54} \mathrm{H}_{4}{ }^{+}$ & 647.235 & $\mathrm{C}_{54}{ }^{-}$ \\
\hline 671.549 & $\mathrm{C}_{56} ; \mathrm{C}_{56} \mathrm{H}_{4}{ }^{+} ; 56 \mathrm{H}_{8}{ }^{+}$ & 671.279 & $\mathrm{C}_{56}{ }^{-}$ \\
\hline 695.603 & $\mathrm{C}_{58}{ }^{+} ; \mathrm{C}_{58} \mathrm{H}_{4}{ }^{+}$ & 695.245 & $\mathrm{C}_{58}{ }^{-}$ \\
\hline 719.672 & $\mathrm{C}_{60}{ }^{+}$ & 719.381 & $\mathrm{C}_{60}{ }^{-}$ \\
\hline- & - & 735.445 & $\mathrm{C}_{60} \mathrm{O}^{-}, \mathrm{C}_{60} \mathrm{OH}_{4}{ }^{-}$ \\
\hline- & - & 767.370 & $\mathrm{C}_{64}{ }^{-}$ \\
\hline 791.549 & $\mathrm{C}_{66}{ }^{+} ; \mathrm{C}_{66} \mathrm{H}_{4}^{+}$ & 792.248 & $\mathrm{C}_{66}{ }^{-}$ \\
\hline 815.593 & $\mathrm{C}_{68} ; \mathrm{C}_{68} \mathrm{H}_{4}{ }^{+}$ & 815.399 & $\mathrm{C}_{68}{ }^{-}$ \\
\hline 839.608 & $\mathrm{C}_{70}{ }^{+}$ & 839.375 & $\mathrm{C}_{70}{ }^{-}$ \\
\hline- & - & 855.568 & $\mathrm{C}_{70} \mathrm{O}^{-}, \mathrm{C}_{70} \mathrm{OH}_{4}^{-}$ \\
\hline
\end{tabular}


Table 2. Results of calculation absolute and relative probability of selection cluster with $\mathbf{n}$ general number of atoms and number of admixture $\mathbf{m}$ atoms in accordance with Eq. (5):

\begin{tabular}{|c|c|c|c|c|c|}
\hline $\mathbf{n}$ & \multicolumn{5}{|c|}{ Admixture atoms ${ }^{13} \mathrm{C}, \mathbf{m}$} \\
\hline & 0 & 1 & 2 & 3 & 4 \\
\hline \multirow{2}{*}{60} & 0,515 & 0,3436 & 0,1127 & 0,024 & 0,004 \\
\cline { 2 - 6 } & 1 & 0,667 & 0,219 & 0,047 & 0,008 \\
\hline \multirow{2}{*}{70} & 0,461 & 0,359 & 0,138 & 0,035 & 0,006 \\
\cline { 2 - 6 } & 1 & 0,778 & 0,299 & 0,065 & 0,013 \\
\hline \multirow{2}{*}{84} & 0,395 & 0,3689 & 0,17 & 0,052 & 0,01 \\
\cline { 2 - 6 } & 1 & 0,933 & 0,43 & 0,132 & 0,025 \\
\hline
\end{tabular}

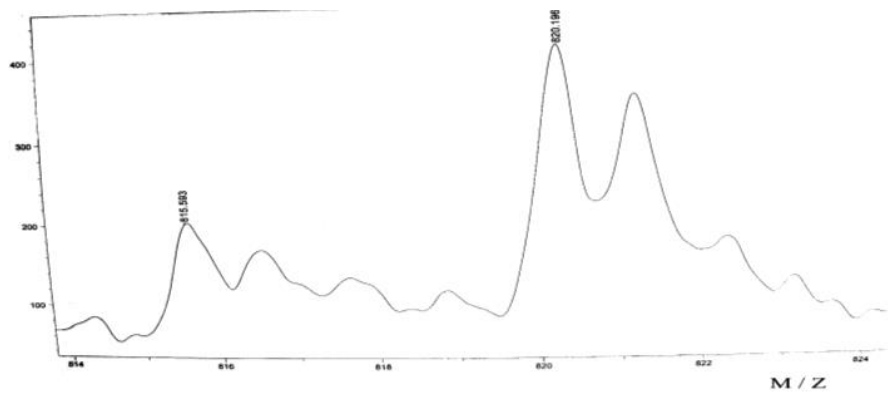

Fig.3. Fragment of MS for clusters' $\mathrm{C}_{56}{ }^{+}, \mathrm{C}_{56} \mathrm{H}_{4}{ }^{+}$and $\mathrm{C}_{56} \mathrm{H}_{8}{ }^{+}$. Fig.2.a increased [16].

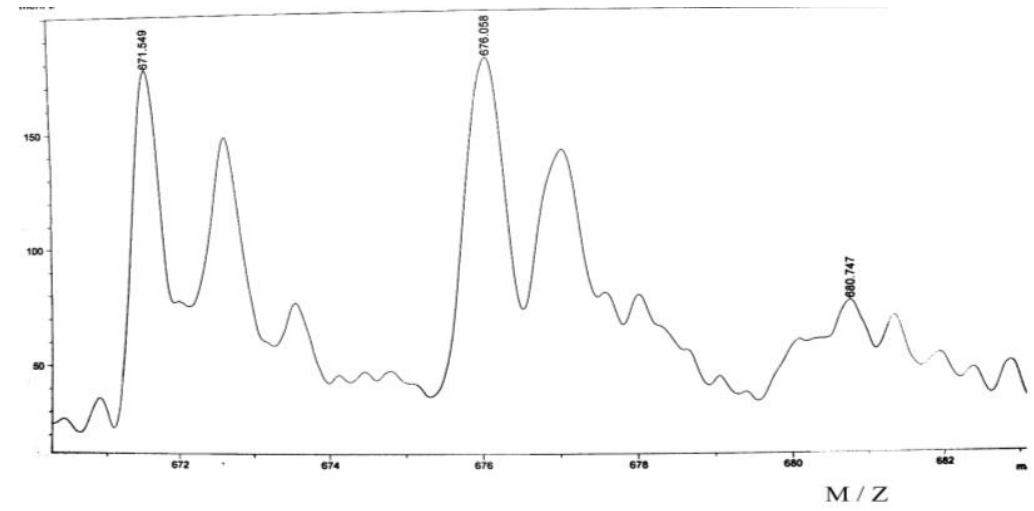

Fig.4. Fragment of MS for clusters' $\mathrm{C}_{68}{ }^{+}, \mathrm{C}_{68} \mathrm{H}_{4}{ }^{+}$from Fig.2.a with increasing [16].

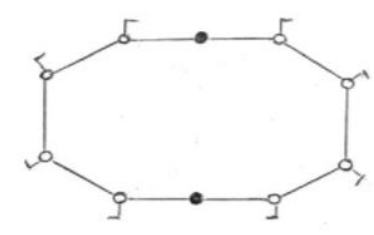

a

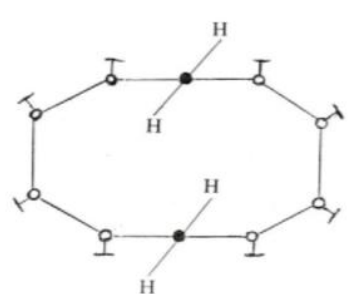

b

Fig.5. The conditional scheme of cluster's fragment of uncompleted fullerene from two hexagons, which would have a general bond across of a few steps between marked points (a), but after chipping off from $2 \cdot \mathrm{H}_{2} \mathrm{O}$ molecules and capturing four hydrogen atoms and after going away atom $\mathrm{O}$ there is the scheme (b). 